ermöglichen, ist der Zugang zu und der Transport von ihren Standorten ein ausserordentlich schwieriger und der Handel wird nicht eher in regelmässige Bahnen zu lenken sein, als bis das Gebiet der zahlreichen Nebenfliusse des AmazonenStroms vollständig geographisch aufgeschlossen ist.

Die Stammpflanzen der Chinarinden sind nach Flückiger und Berg angegeben, wie folgt:

$$
\begin{aligned}
& \text { Cort. Ch. regia: } \\
& \text { - Loxa: } \\
& \begin{array}{ll}
- & \text { - Huanoco: } \\
-\quad & \text { - Huamalies: }
\end{array} \\
& \text { C. Calisaya } \\
& \text { - macrocalix } \\
& \text { - heterophylla } \\
& \text { Chahuarguera } \\
& \text { - Uritusinga } \\
& \text { - micrantha } \\
& \text { - scrobiculata } \\
& \text { - Condaminea } \\
& \text { - - flava dura laevis: - cordifolia } \\
& \text { - - - - suberosa: - lutea } \\
& \text { - - fibrosa: - lancifolia } \\
& \text { - - rubra: - succirubra } \\
& \text { - - rubiginosa: - pubescens. }
\end{aligned}
$$

Die Verbreitung der einzelnen Arten ist aus der Karte ersichtlich, ein näheres Eingehen darauf daher überflüssig, auch lag es nicht in meiner Absicht die Ausbreitung jeder Art bis in die kleinsten Umrisse graphisch darzustellen, da, abgesehen von der Schwierigkeit einer solchen Arbeit, das genügende Material dazu noch lange nicht vorhanden ist.

\title{
Kupferhaltige Speisen.
}

Von Dr. Eugen Holdermann, Apotheker in Heidelberg.

Es ist eine bekannte üble Gewohnheit der Köchinnen, dass sie den für die Tafel bestimmten sauren Gurken dadurch eine feurig grüne Farbe zu verleihen sich gegenseitig wetteifern, dass sie dieselben in mit Essig befeuchtetem Zustande in kupfernen Gefässen einige Zeit der Wirkung des atmosphärischen Sauerstoffs aussetzen. 
Der Erfolg dieser Manipulation ist allerdings ein das Auge bestechender, wie sich jedoch der Magen, dem diese mit Kupfirsalz imprägnirten Gurken aufoctroirt werden, hierzu verhüll, dies ist eine Frage, über die sich die auf die schönen Essiggurken stolze Köchin weiter keine Gedanken macht.

Derartige ausserordentlich schön grün gefürbte Essiggrurken bildeten mir vor einiger Zeit den Gegenstand einer quantitativen Ermittlung des Kupfergehaltes und ich gestatte mir, deren Resultat an dieser Stelle zu veröffentlichen, damit sich die geehrten Leser ein Urtheil bilden können, in wie weit die häufig gebrauchte Redensart „So ein Bischen Kupfer sehadet Nichts" gerechtfertigt ist.

Es wurde zunächst zur qualitativen Prüfung eine Gurke getrocknct und unter Zusatz von salpetersaurem Kali verascht, die erhaltene Asche in Salpetersäure aufgenommen, filtrirt und das Filtrat zur 'Trockene rerdunstet. Der dabei bleibende Rückstand gab mit Borax die für Kupfer charakteristische blaue Perle in der Oxydationsflamme, es war somit das Vorhandensein von Kupfer in nachweisbarer Menge constatirt.

Die quantitative Bestimmung wurde mit der von sechs Stück mittelgrosser Gurken erhaltenen Asche vorgenommen. Sie wurde in Salpetersüure gelöst, die Lösung zur Verjagung der überschüssigen Säure wieder zur 'Trockene verdampft, der Rückstand in salzsäurehaltigem Wasser anfgelöst und durch diese I.ösung ein Strom gewaschenen Schwefelwasserstoffgases geleitet. Inas ausgeschiedene Schwefelkupfer wurde in Salpetersäure gelöst und aus dieser Lösung das Kupferoxyd durch Kali in der siedhitze getällt.

Das Gewicht des geglühten Kupferoxydes betrug nach Abzug der Filterasche 0,045 g., was sich nur schwierig in eine Bezichung zu der Menge der angewandten Substanz bringen lässt, da ja eine l'rocentberechnung auf Gurken kaum zulässig sein dürfte.

Um jedoch zu einer concreten Vorstellung über die Bedeutung des gefundenen Kupfergehaltes zu gelangen, berechnete ich denselben als Kupfersulfat, für das die Pharm. Germ. 
eine Maximaldosis normirt hat und stellte die so berechnete Menge der Stückzahl der angewandten Essiggurken gegeniiber.

Es berechnet sich alsdann folgendermaassen:

$0,045 \mathrm{~g}$. Kupferoxyd sind enthalten in $0,14 \mathrm{~g}$. Kupfersulfat und ebenso in den zur Untersuchung verwendeten 6 Stiick Gurken, es enthält mithin jede Gurke durchschnittlich die Kupfermenge von $0,023 \mathrm{~g}$. Sulfat. Die Pharm. Germ. lat die Einzelmaximaldosis des Kupfersulfats auf 1 Decig. normirt, welche Menge man etwa beim Verspeisen der vierten Gurke erreicht hat.

Sind auch 4 Gurken von der Grösse der untersuchten für einen normalen Apretit als Beilage zum Rindfeisch mehr als ausreichend, so ist dennoch kein Grund einzusehen, warum man sich für das schöne Aussehen mit der Rindfleischbeilage eine so bedentende Menge Kupfer einverleiben solllte. Denn, wenn diese Menge auch nicht geradezu giftig wirkt, so dürtte sie doch bisweilen in einer nicht gerade zuträglichen Weise ihren Einfluss auf unsern Verdaungsapparat zur Geltung bringen.

Auffallend war bei dieser Unter'suchung der Umstand, dass der die Gurken umgebende Essig nicht, wie dies voriursgesetzt wurde, besonders kupferhaltig war, sondern nur ranz unbedeutende Spuren davon enthiclt. Ich erkläre mir dies so, dass sich entweder das gesammte in Jösung gegangene Kupfersalz in organischer Vorbindung auf dem Gewebe der Gurken niedergeschlagen hat und ron diesen fixirt wurde, oder, dass der Essig vor dem Serviren durch neuen ersetzt wurde. Der ursprüngliche Essig war mir leider in diesem Falle nicht zugäinglich.

\title{
Ueber eine phosphorsäurehaltige Salzsăure.
}

\author{
Von Demselben.
}

Vor einigen Monaten hatte Einsender unter einer grösseren direct von einer chemischen Fabrik bezogenen Waaren- 